\title{
Examination of Emergency Medicine Physicians' and Residents' Twitter Activities During the First Days of the COVID-19 Outbreak
}

\author{
Mustafa Boğan ${ }^{1 *}$, Mehmet Karadağ², Fatma Boğan ${ }^{3}$ \\ ${ }^{1}$ Emergency Department, Medicine Faculty, Düzce University, Düzce, Turkey \\ ${ }^{2}$ Department of Biostatistics, Medicine Faculty, Hatay Mustafa Kemal University, Hatay, Turkey \\ ${ }^{3}$ Health Research and Application Hospital, Düzce University, Düzce, Turkey \\ Corresponding Author: Mustafa Boğan, MD, PhD, Emergency Department, Medicine Faculty, Düzce University, Düzce, \\ Turkey. Tel: +90-506 94044 25, Email: mustafabogan@hotmail.com
}

Received April 3, 2020; Accepted April 25, 2020; Online Published May 9, 2020

\begin{abstract}
Introduction: Social media has become an important element of interaction and found itself a place in every aspect of our lives. This study examined the twitter activities of emergency medicine physicians and residents (EMP\&R) about the COVID-19 outbreak.

Methods: The study concentrated on Twitter, a major social media network. To identify accounts owned by EMP\&R, followers of the official accounts of two emergency medicine physician associations in our country were reviewed.

Results: In total, 251 accounts whose owners stated they were EMP\&R in their biographies, were public, and had tweeted within the last year were identified. Among the 210 tweets posted about coronavirus, 42.4\% contained comments and suggestions, $18.6 \%$ institutional announcements, $17.1 \%$ news, $14.8 \%$ scientific content, and $7.1 \%$ contained humor.

Conclusion: This study examined the importance of Twitter posts during outbreaks and the attitudes of emergency medicine doctors on this issue. Based on the results, it is thought that EMP\&R should share more.

Keywords: Social Media, Emergency Medicine, Disease Outbreaks, Coronavirus
\end{abstract}

Citation: Boğan M, Karadağ M, Boğan F. Examination of emergency medicine physicians' and residents' Twitter activities during the first days of the COVID-19 outbreak. Int J Travel Med Glob Health. 2020;8(2):46-50. doi:10.34172/ijtmgh.2020.08.

\section{Introduction}

Social media has become an important element of interaction and has found itself a place in every aspect of our lives. It is a platform through which many topics, such as job advertisements, shopping, romantic gestures, personal comments, and scientific publications, can be shared; it also facilitates addressing wide audiences. Founded in 2006, Twitter is one of the most important social media networks with free access and a wide user base. ${ }^{1}$ It is a microblogging site originally developed for mobile phones and designed to enable users to post tweets of up to 140 words. Users are asked to answer the question, "What are you doing?" by forming a constantly updated timeline with tweets of various types from humor to breaking news. ${ }^{2}$ Some evidence suggests that social media could play a role during disease outbreaks, emergency responses, and relief efforts. ${ }^{3}$ It is known that the Centers for Disease Control and Prevention (CDC) used social media networks such as Twitter and Instagram to inform the public and manage the crisis during the H1N1 outbreak. ${ }^{4}$

Several occupational groups can address both their colleagues and their consultants/clients through Twitter. It is known that emergency medicine doctors also widely use Twitter and that emergency department visits can particularly increase during outbreaks. ${ }^{5,6}$ By using Twitter, an important mass communication platform, it is possible to reach wide audiences. The novel coronavirus outbreak that is reported to have begun in the city of Wuhan, China in late December 2019 or mid-January 2020 has had serious effects not only because of its physical presence, but also due to the awareness raised by Dr. Li Wenliang through social media. ${ }^{7}$

In this study, which was prepared considering that public awareness could be raised by awareness efforts on social media and that doing so could prevent emergency service overcrowding, the Twitter activities and sensitivity to the subject among emergency medicine physicians and residents (EMP\&R) were examined.

Copyright (C) 2020 The Author(s). This is an open-access article distributed under the terms of the Creative Commons Attribution License (http:// creativecommons.org/licenses/by/4.0), which permits unrestricted use, distribution, and reproduction in any medium, provided the original work is properly cited. 


\section{Methods}

This descriptive study was conducted via Twitter, a major social media network, in Turkey and included Turkish tweets between December 31, 2019 and January 31, 2020. The tweets were evaluated retrospectively.

The time frame for the study was determined based on the report published by the World Health Organization (WHO) on January 21, 2020. ${ }^{8}$ Based on this report, pneumonia cases of unknown etiology and cause were reported on December 31, 2019; Chinese sources announced that it was a new type of virus on January 7, 2020, and the WHO declared an "international public health emergency" on January 30, 2020. In line with these dates, tweets posted by Twitter accounts determined to belong to EMP\&R during the first month of the outbreak (FMO) (December 31, 2019 - January 31, 2020) were included in the study. To identify the accounts owned by EMP\&R, the followers of the official accounts of two emergency medicine physician associations in our country were reviewed. Among these profiles, those that had the statements "emergency medicine specialist", "emergency physician", "emergency doc", "EP", “emergency specialist”, "emergency responsible", "emergency resident", or "emergency medicine resident" were evaluated. Of these profiles, those that had posted in the last year, posted in Turkish, and were public were included in the study. The tweets posted by the relevant accounts during the FMO were read one by one to identify their contents. The data was entered into preprepared forms. The number of followers, the total number of tweets, and the number of tweets during the FMO of the accounts included in the study were recorded; afterwards, the tweets about coronavirus (those including the phrases "coronavirus", "Wuhan", "outbreak") among them were categorized. The categories were: "comments/suggestions", "humor", "announcements of government institutions or nongovernmental organizations", "news", and "scientific content". The data was then analyzed.

\section{Statistical Method}

The Shapiro-Wilk test was used to determine if the data was normally distributed. The Spearman correlation coefficient was used to test the relationships between numerical variables that did not demonstrate normal distribution. The strength of the correlation coefficient was interpreted as poor when between 0.2-0.4, moderate when between 0.4-0.6, strong when between $0.6-0.8$, and very strong when between $0.8-1 .{ }^{9}$ As descriptive statistics, the mean \pm standard deviation was used for numerical variables and the number and percentage values were presented for categorical variables. The SPSS bundle program version 24.0 was used for statistical analyses, and a $P$ value of $<0.05$ was considered statistically significant.

\section{Results}

In total, 251 accounts stating that the owners were emergency medicine physicians/residents in their biographies, were public, and had tweeted within the last year were identified. It was determined that $167(66.5 \%)$ of these accounts had tweeted within the FMO. It was observed that the first tweets about the outbreak were retweets of news related to the subject on the 6th of January. It was further observed that these accounts had an average of $317.69 \pm 524.96$ followers, and that the average number of tweets was $1051.53 \pm 1862.32$. The relevant accounts had posted $14.89 \pm 44.48$ tweets during the FMO. All accounts evaluated had posted a total of 210 tweets about the coronavirus outbreak; an average of $0.84 \pm 3.82$ tweets had been posted per account. Among the 210 tweets posted about coronavirus, $42.4 \%$ contained comments and suggestions, $18.6 \%$ institutional announcements, $17.1 \%$ news, $14.8 \%$ scientific content, and $7.1 \%$ contained humor (Table 1 ).

A strong positive meaningful correlation was identified between the number of followers and the number of tweets posted $(\mathrm{r}=0.768, \quad P=0.001)$. A positive but moderately meaningful correlation was identified between the number of tweets posted during the determined FMO and the total number of tweets $(\mathrm{r}=0.461, P=0.001)$. A positive but once again moderately meaningful correlation was identified between the number of tweets posted during the FMO and the number of tweets related to coronavirus $(r=0.478, P=0.001)$. A strong positive correlation was identified between the number of tweets posted during the FMO and the number of tweets with scientific content related to coronavirus $(\mathrm{r}=0.650 ; P=0.009)$. A meaningful strong correlation was found between the number of tweets related to coronavirus and tweets containing comments/suggestions, humor, official institutional announcements, and scientific content (Table 2).

A strong positive meaningful correlation was identified between the number of tweets posted during the FMO and the number of cases and countries with cases $(r=0.793,0.724$, respectively; $P=0.001$ ) (Table 3 ).

As Figure 1 demonstrates, as the number of cases in a country increased, the number of tweets also increased at the same rate. While the levels of tweets posted from the relevant accounts at the start of the dates determined appeared insignificant, starting on January 22, a sharp increase in the number of tweets was observed. Although there was a shortterm drop in the number of tweets posted starting from the 24th of January, sharp increases followed by a drop were observed on the 25th of January. Finally, the number of tweets was observed to continue rising. As of January 31, the number

Table 1. Descriptive Statistics

\begin{tabular}{lcc}
\hline & Total & Mean (SD) \\
\hline Total number of accounts & 251 & - \\
No. of followers of accounts & 79740 & $317.69(524.96)$ \\
Total number of tweets by accounts & 263933 & $1051.53(1862.32)$ \\
No. of tweets by accounts during FMO & 3737 & $14.89(44.48)$ \\
No. of coronavirus-related tweets, No. (\%) & $210(100 \%)$ & $0.84(3.82)$ \\
\hline Comment/suggestion n(\%) & $89(42.4 \%)$ & $0.35(2.16)$ \\
\hline Humor n(\%) & $15(7.1 \%)$ & $0.06(0.37)$ \\
\hline Institutional announcement $\mathrm{n}(\%)$ & $39(18.6 \%)$ & $0.16(0.76)$ \\
\hline News n(\%) & $36(17.1 \%)$ & $0.14(0.98)$ \\
\hline Scientific n(\%) & $31(14.8 \%)$ & $0.12(0.62)$ \\
\hline
\end{tabular}

SD, standard deviation. 
Table 2. Examination of the Relationship Between Followers, Tweets, and Subjects

\begin{tabular}{|c|c|c|c|c|c|c|c|c|c|}
\hline & & $\begin{array}{l}\text { Total Number } \\
\text { of Tweets }\end{array}$ & $\begin{array}{l}\text { No. of Tweets } \\
\text { During FMO }\end{array}$ & $\begin{array}{l}\text { No. of Corona- } \\
\text { Related Tweets }\end{array}$ & $\begin{array}{l}\text { Comment/ } \\
\text { Suggestion }\end{array}$ & Humor & $\begin{array}{l}\text { Official Institutional } \\
\text { Announcement }\end{array}$ & News & Scientific \\
\hline \multirow{2}{*}{ No. of followers } & $\mathrm{R}$ & $0.768^{* *}$ & $0.338^{* *}$ & $0.322^{* *}$ & 0.346 & $0.848^{* *}$ & 0.375 & 0.295 & 0.273 \\
\hline & $\mathrm{P}$ & 0.001 & 0.001 & 0.001 & 0.066 & 0.008 & 0.138 & 0.285 & 0.325 \\
\hline \multirow{2}{*}{$\begin{array}{l}\text { Total number of } \\
\text { tweets }\end{array}$} & $\mathrm{R}$ & & $0.461^{* *}$ & $0.323^{* *}$ & $0.398^{*}$ & $0.913^{* *}$ & 0.447 & 0.208 & 0.223 \\
\hline & $\mathrm{P}$ & & 0.001 & 0.001 & 0.033 & 0.002 & 0.072 & 0.457 & 0.425 \\
\hline \multirow{2}{*}{$\begin{array}{l}\text { No. of tweets } \\
\text { during FMO }\end{array}$} & $\mathrm{R}$ & & & $0.478^{* *}$ & $0.486^{* *}$ & 0.261 & 0.305 & 0.434 & $0.650^{* *}$ \\
\hline & $\mathrm{P}$ & & & 0.001 & 0.008 & 0.533 & 0.233 & 0.106 & 0.009 \\
\hline \multirow{2}{*}{$\begin{array}{l}\text { No. of corona- } \\
\text { related tweets }\end{array}$} & $\mathrm{R}$ & & & & $0.790^{* *}$ & $0.759^{*}$ & $0.877^{* *}$ & $0.567^{*}$ & $0.895^{* *}$ \\
\hline & $\mathrm{P}$ & & & & 0.001 & 0.029 & 0.001 & 0.027 & 0.001 \\
\hline
\end{tabular}

r: Spearman correlation coefficient; ${ }^{* *}$ Correlation is significant at the 0.01 level; ${ }^{*}$ Correlation is significant at the 0.05 level.

Table 3. Examination of the Relationship Between the Number of Corona-Related Tweets and the Numbers of Countries and Cases

\begin{tabular}{cccc}
\hline & & No. of Cases & No. of Countries \\
\hline Number of corona-related tweets & $\mathrm{r}$ & $0.793^{* *}$ & $0.724^{* *}$ \\
& $P$ & 0.001 & 0.001 \\
& $\mathrm{n}$ & 11 & 11 \\
\hline
\end{tabular}

** Correlation is significant at the 0.01 level; * Correlation is significant at the 0.05 level.

of tweets posted had reached 40 tweets. Google searches about the coronavirus originating from Turkey have increased since January 21, 2020.

\section{Discussion}

If Dr. Li Wenliang, who died from the novel coronavirus on February 7, 2020, had not announced the outbreak of a dangerous new virus through social media, measures would perhaps have been delayed even further. ${ }^{7}$ This example that demonstrates the impact of social media has prompted the investigation of posts shared by EMP\&R related to coronavirus on Twitter, which is one of the most widely used social media networks with more than 300 million users. In Turkey, it is known that sharing on Twitter occurs mostly on Monday, Tuesday, Wednesday, and Thursday between 17:0019:00 and 20:00-23:30.10

The current study determined that on January 28, 29, and 30, 2020 (Tuesday, Wednesday, and Thursday) between
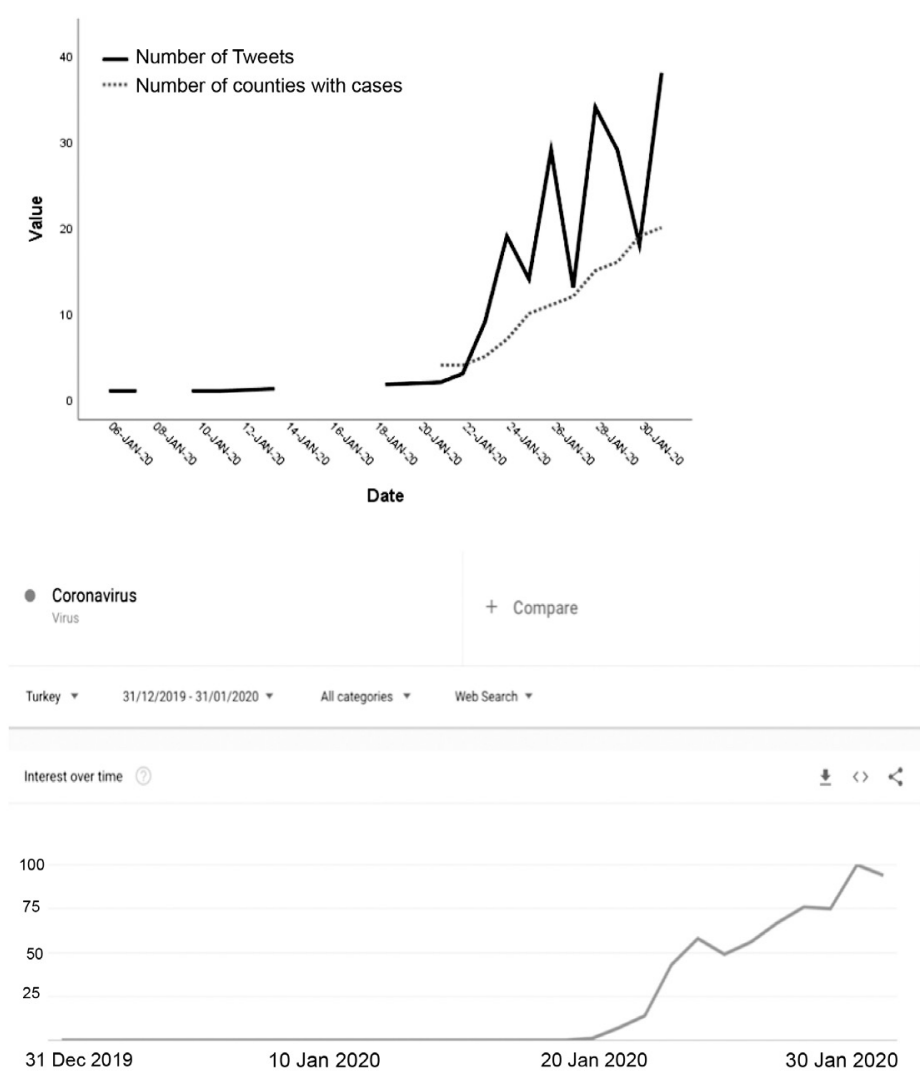

Figure 1. The Changes in Country With Cases and Tweets Over Time and the Graph of Google Searches Related to "Coronavirus" From Turkey. 
the hours 21:00-22:00, an average of 104.7 tweets related to "coronavirus" were posted per hour. During the FMO, a total of 210 tweets related to the outbreak were posted from the 251 accounts included in the study. It was observed that $66.5 \%$ of these accounts tweeted actively during these dates and that an average of 1051.53 tweets were posted. Lulic and Kovic identified that more than half of the accounts belonging to emergency medicine specialists included in their study posted during the 15-day study period, and that an average of 81.5 tweets had been posted. ${ }^{1}$ Computers, tablets, and smartphones are becoming increasingly common all over the world, regardless of the socio-economic situation. Information can be spread rapidly through the Internet and social media, but it is becoming increasingly difficult to prove the accuracy of this information. ${ }^{11}$ It is becoming increasingly common for some institutions to actively utilize social media to manage and direct the public, especially in disasters. ${ }^{12}$

It is also believed that sharing information on personal Twitter accounts could strengthen the patient-doctor relationship and cooperation and improve the quality of healthcare. ${ }^{13}$ However, a high rate of non-medical tweets posted by accounts stating in their profiles that the owners are doctors has been reported. ${ }^{14}$ It is known that misinformation increases overcrowding in emergency departments and that both official institutions and people correct this misinformation via Twitter., ${ }^{4,611}$ However, studies have demonstrated that official accounts almost always use Twitter one-sidedly. ${ }^{3}$ Therefore, it is important that the personal Twitter accounts of EMP\&R who could communicate interactively should be utilized more actively to inform their followers. A strong positive correlation was observed between all tweets posted by the emergency medicine community during the FMO and tweets with scientific content $(r=0.650$; $P=0.009$ ). This shows that the EMP\&R aimed to enlighten their followers about the subject. Health professionals are also known to engage in dangerous behaviors such as violating patient confidentiality with their tweets, engaging in unethical behavior, or not taking the potential negative effects of the tweets they publish seriously. ${ }^{15}$

Therefore, it is believed that the scientific content in tweets posted by EMP\&R at a higher frequency than personal comments/suggestions which could lead to adverse outcomes is a significant improvement. However, it was still observed that among the 210 tweets posted by accounts of people who specialized in emergency medicine, the highest proportion was comments/suggestions. The interpretation-based operation of these platforms, which are capable of spreading information, is one of the notable features. In addition, when the corona-related tweets were evaluated, it was seen that the frequency of tweets with news content was low. The fact that the frequency of tweets increased as the number of cases and countries with cases increased suggests that EMP\&R did not become aware of the situation early and that the effort for awareness was not started early.

\section{Limitations}

- The fact that emergency medicine specialists and residents who did not follow either of the two associations on Twitter were not included in the study could be considered a serious limitation.

- It is thought that most emergency medicine specialists and residents on Twitter were not reached, because Twitter accounts that did not state the account owner was an emergency medicine specialist or resident on their profile biographies were not included in the study.

- Emergency medicine specialists and residents may have used different social media platforms; because this study was conducted only on Twitter, it may not provide reasonable insight into other social media networks.

\section{Conclusion}

Although EMP\&R became aware of the novel coronavirus outbreak late, they did make an effort to raise awareness by sharing scientific content. The current study examined the importance of Twitter posts during outbreaks and the attitudes of emergency medicine doctors on this issue. Based on the results, it is thought that EMP\&R should share more. From this perspective, it is believed that the social role of personal comments, news and scientific shares on Twitter is a topic that will continue to be discussed.

\section{Authors' Contributions}

$\mathrm{MB}$ contributed to conception; $\mathrm{MB}$ contributed to design; $\mathrm{MK}$ contributed to supervision; $\mathrm{MB}$ and FB contributed to data collection and processing; MK contributed to analysis and interpretation; $\mathrm{MB}$ and $\mathrm{FB}$ contributed to literature review; $\mathrm{MB}$ and $\mathrm{FB}$ contributed to writing; $\mathrm{MB}$ and $\mathrm{MK}$ contributed to critical review.

\section{Conflict of Interest Disclosures}

The authors declare they have no potential conflicts of interest with respect to the research, authorship, and/or publication of this article.

\section{Ethical Approval}

All information collected from this study was from public Twitter accounts. Protected accounts were excluded from the study. Ethics approval was not required for this study. Authors declare that human rights were respected according to the Declaration of Helsinki.

\section{Funding/Support}

The authors received no financial support for the research, authorship, and/or publication of this article.

\section{Research Highlights}

What Is Already Known?

Social media could play a major role during emergency responses and relief efforts.

What This Study Adds?

EMP\&R made efforts to raise awareness by sharing scientific content. 


\section{Acknowledgments}

The authors express their respect of Dr. Li Wenliang.

\section{References}

1. Alnemer KA, Alhuzaim WM, Alnemer AA, et al. Are healthrelated tweets evidence based? review and analysis of healthrelated tweets on Twitter. J Med Internet Res. 2015;17(10):e246. doi:10.2196/jmir.4898.

2. Williams SA, Terras M, Warwick C. How Twitter is studied in the medical professions: a classification of Twitter papers indexed in PubMed. Med 2 0. 2013;2(2):e2. doi:10.2196/med20.2269.

3. Neiger BL, Thackeray R, Burton SH, Thackeray CR, Reese JH. Use of twitter among local health departments: an analysis of information sharing, engagement, and action. J Med Internet Res. 2013;15(8):e177. doi:10.2196/jmir.2775.

4. Guidry JPD, Jin Y, Orr CA, Messner M, Meganck S. Ebola on Instagram and Twitter: how health organizations address the health crisis in their social media engagement. Public Relat Rev. 2017;43(3):477-486. doi:10.1016/j.pubrev.2017.04.009.

5. Lulic I, Kovic I. Analysis of emergency physicians' Twitter accounts. Emerg Med J. 2013;30(5):371-376. doi:10.1136/ emermed-2012-201132.

6. Shapiro JS, Genes N, Kuperman G, Chason K, Richardson LD. Health information exchange, biosurveillance efforts, and emergency department crowding during the spring 2009 H1N1 outbreak in New York City. Ann Emerg Med. 2010;55(3):274-279. doi:10.1016/j.annemergmed.2009.11.026.

7. Fei LY. He Warned of Coronavirus. Here's What He Told Us
Before He Died. The New York Times. February 7, 2020. https:// www.nytimes.com/2020/02/07/world/asia/Li-Wenliang-chinacoronavirus.html. Accessed February 22, 2020.

8. World Health Organization (WHO). Novel Coronavirus (2019nCoV) Situation Report - 121 January 2020. WHO; 2020. https:// www.who.int/emergencies/diseases/novel-coronavirus-2019/ situation-reports.

9. Salkind NJ, Frey BB. Statistics for People Who (Think They) Hate Statistics. Sage Publications Inc; 2019.

10. Avcıoğlu B. Sosyal Medyada Etkileşimi Artıran Paylaşım Saatleri. Digitalge website. https://digitalage.com.tr/sosyal-medyadaetkilesimini-artiran-paylasim-saatleri. Accessed February 12, 2020. Published July 21, 2017.

11. Oyeyemi SO, Gabarron E, Wynn R. Ebola, Twitter, and misinformation: a dangerous combination? BMJ. 2014;349:g6178. doi:10.1136/bmj.g6178.

12. Houston JB, Hawthorne J, Perreault MF, et al. Social media and disasters: a functional framework for social media use in disaster planning, response, and research. Disasters. 2015;39(1):1-22. doi:10.1111/disa.12092.

13. Pershad $\mathrm{Y}$, Hangge PT, Albadawi H, Oklu R. Social medicine: Twitter in healthcare. J Clin Med. 2018;7(6). doi:10.3390/ jcm7060121.

14. Gagnon K, Sabus C. Professionalism in a digital age: opportunities and considerations for using social media in health care. Phys Ther. 2015;95(3):406-414. doi:10.2522/ptj.20130227.

15. Alpert JM, Womble FE. Just what the doctor tweeted: physicians' challenges and rewards of using Twitter. Health Commun. 2016;31(7):824-832. doi:10.1080/10410236.2015.1007551 